\title{
Los outsiders en el Perú
}

Milton Ovidio Pastor Neyra* http://dx.doi.org/10.21503/lex.v10i10.228

* Catedrático de la Universidad Alas Peruanas y otras universidades, licenciado en Ciencia Política. Licenciado en Educación, especialidad de Filosofía y Ciencias Sociales. Máster en Ciencia Política.

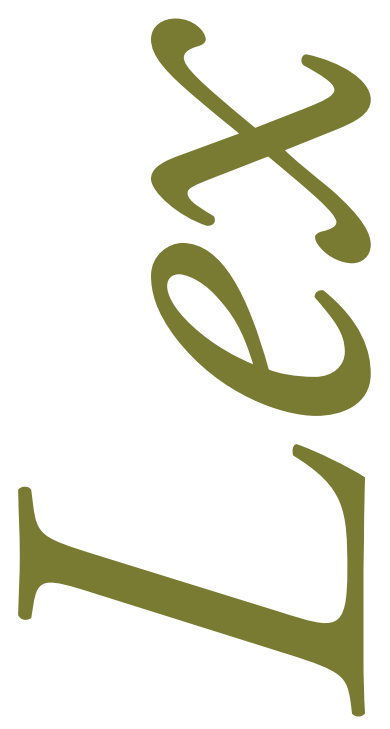





\section{¿Qué es un outsider?}

En general, es un individuo que viene de fuera del sistema de partidos y de la sociedad política, con un prestigio ganado en otra actividad, diferente de la política, y por estas razones, en una situación de crisis de una forma de representación, la gente se inclina a confiar en ella o él.

Contrariamente a lo que se ha dicho de manera espontánea, sí constituye una forma de representación política, aunque esta forma no sea, necesariamente, democrática. Es una forma de representación por identificación, o de representación simbólica, en la que los individuos tienden a identificarse directamente con el líder que consideran, por no estar mezclado con los políticos tradicionales, capaz de solucionar sus problemas. Su aparición, además, suele coincidir con el surgimiento de una nueva organización política, que es el que impulsa la candidatura de esta figura política.

El outsider desarrolla un discurso condenatorio de la política y los políticos, a los que señala como la causa de los males que vivimos, es decir, posee un discurso antisistema en muchos casos o apolítico en otros, y a veces combina ambos o en otros su falta de claridad al respecto no permite determinar de forma correcta cuál es el sentido real de lo que manifiesta.

Busca aparecer, de esta forma, incluso cuando desarrolla su papel como líder, ajeno a la política misma. En otras palabras, es un político que dice que no hace política y que señala que nada se puede conseguir a través de la actividad política. Por lo tanto, no le queda otro camino que hacer política en las sombras, huyendo del escrutinio público. Su relación con la población no la entiende como un acto deliberativo, de intercambio de opiniones sobre los temas del poder, sino como un acto de relaciones públicas, para dar o recibir cosas, o, a lo sumo, comunicar decisiones ya tomadas a la ciudadanía. Es un político, entonces, que desarrolla una actitud antipolítica, aun cuando en su pasado puede haber tenido o estar relacionado con alguna organización partidaria. 
Hay diferentes tipos de outsiders. Tenemos, por una parte, personajes como Alberto Fujimori, un completo outsider en la sociedad política del Perú al final de la década de 1980, que gana la elección presidencial incluso contra los medios de comunicación masiva que apoyaban al candidato rival. Este es además un claro ejemplo de cómo un personaje que estuvo vinculado a la política desde la actividad universitaria terminó desarrollando un discurso antipolítico que lo llevó a convertirse en Presidente el año 1990.

Otro outsider como Fernando Collor de Melo es prácticamente fabricado como candidato ganador por las grandes cadenas de televisión brasileñas a principios de la década de 1990 . Igualmente, suceden cosas como la candidatura de Mario Vargas Llosa, en el Perú, como reacción a típicas políticas populistas, que terminó siendo absorbida por los partidos de la derecha tradicional, o sea un outsider que terminó de insider. Por último, tenemos el caso de artistas como Palito Ortega, que son llamados por un partido político, el peronista en este caso, para postular a un puesto de elección popular en razón de su prestigio obtenido como cantante. Es decir, el caso de un partido que se aprovecha del fenómeno outsider para levantar sus bonos.

El outsider propone una relación "directa" pero no deliberativa con la ciudadanía, por encima de las instituciones representativas, que albergarían a los políticos, y al margen de las reglas de juego. La ciudadanía, por su parte, cansada de un régimen político poco eficaz pero formalmente basado en reglas, prefiere cambiar la vigencia de tales reglas por su confianza en la capacidad personal del líder (Perelli, 1995). Para esta relación directa, el outsider privilegia el uso de los medios de comunicación masiva, en especial la televisión, que para algunos sería el nuevo vehículo de agregación de intereses, cultivando con esmero una imagen cercana a la mayoría ciudadana.

Este outsider, además, aparece siendo eficaz, es decir, brindando soluciones, no importa a qué precio, que los partidos no habían sabido ofrecer. Su fuente de legitimidad son por eso los resultados aparentes, fruto de la aplicación decidida de determinadas políticas. La legitimidad por resultados se convierte entonces en un soporte fundamental, generalmente por encima de la legitimidad legal-democrática que se obtiene en las urnas.

Así tenemos que este fenómeno puede significar diferentes cosas. Por un lado, el surgimiento de nuevos líderes, especialmente locales y regionales, que nacen de la sociedad civil para llenar el vacío dejado por la crisis de los partidos que ya explicamos anteriormente. Por otro, la nueva apariencia que deben tomar antiguos líderes partidarios, que se desligan de sus organizaciones originales, para volver a la actividad política con alguna perspectiva de éxito. Por último, la posibilidad para todo género de aventureros de incursionar en la actividad política entendiéndola como un negocio particular. Pero en todos los casos se trata 
de aparecer como nuevos intermediarios que no tienen compromisos con el antiguo orden partidario establecido.

Hay diferentes explicaciones, de carácter más bien estructural, para entender el origen de los outsiders. Sergio Zermeño (1989) pone el énfasis en la crisis del Estado como agente dinamizador de la sociedad, y en particular del modelo de industrialización, que habría llevado a la desaparición de buena parte de la clase trabajadora industrial en América Latina. Esto lleva a una multiplicación de la población excluida del sector moderno de la economía y la sociedad, así como a una fortísima erosión de la base social de los partidos populistas y de izquierda.

Carina Perelli (1995) y Óscar Landi (1995) subrayan los cambios de tipo cultural. Los viejos canales de intermediación, educación y agregación de demandas, como la educación cívica escolar, la prensa escrita y los partidos, se demuestran obsoletos, dando paso a medios masivos de comunicación como la televisión y a formas de medición de la opinión pública como las encuestas. Se desarrolla de esta forma una comunicación no de masas sino mediática, sin interacciones sociales, que se dirige a individuos atomizados. Esta nueva situación, paradójicamente, crea una cultura de imágenes en la que es posible observar lo que está pasando en distintas partes del planeta casi de manera simultánea a la ocurrencia de los hechos, y, a la vez, hace posible un acceso mucho mayor de los individuos a la información. En este nuevo contexto, los políticos ya no son necesarios en su antiguo papel de intermediarios, y para mantener su vigencia deben negociar su agenda con un nuevo poder dominante como son los medios de comunicación, convirtiéndose en los casos extremos en productos de los mismos.

En estas condiciones, la política se convierte en un espectáculo que se presenta a la población, más que afirmarse como un proceso en cual la población participe. Así, la política se va mudando de sus lugares habituales como el Parlamento, y los políticos elegidos van siendo reemplazados por los técnicos en la toma de las decisiones fundamentales del Estado.

Estos cambios, de tipo tanto sociopolítico como cultural, tienen un impacto distinto en los diferentes países, de acuerdo a la consistencia de los sistemas de partido y el nivel de institucionalización respectivo. En el caso peruano, un sistema débil o inexistente de partidos y una baja institucionalización de los mismos ha sido un escenario propicio para la aparición de outsiders, sumado a ello las condiciones que el mismo sistema electoral favorecía para el surgimiento de estas figuras políticas.

En algunos casos, los sistemas partidarios son capaces de absorber, o al menos convivir con el reto de los outsiders y la creciente influencia política de los medios; en otros, la debilidad del sistema partidario lleva a que sucumban frente a los outsiders, llevando al colapso al sistema de 
partidos, como fue el caso peruano en los años noventa. Sin embargo, como ya explicáramos, en los distintos ejemplos que podamos presentar, hay necesidad de la crisis de un sistema de representación anterior para que la alternativa de los outsiders, como intento de una nueva forma de representación, sea viable.

En el Perú, el surgimiento del fenómeno de independientes u outsiders está directamente ligado a la crisis de los partidos en la década de 1980. El fenómeno empieza expresándose dentro del propio sistema partidario de la época, en la tradicional personalización de la política partidaria, en la proliferación de figuras independientes que hacen política con los partidos, y en alcaldes distritales y provinciales que empiezan a presentarse claramente como distintos de los partidos. Pero alcanza su plenitud cuando los partidos se muestran agotados y dejan el espacio para que aparezca una persona totalmente diferente de los políticos tradicionales.

Es el momento del surgimiento de Alberto Fujimori en las elecciones generales de 1990. Es cierto que un año antes Ricardo Belmont ya había ganado las elecciones municipales de la capital presentándose con su propia agrupación independiente y con un discurso apolítico, derrotando a la hasta entonces más fuerte coalición de partidos denominada FREDEMO. Además de las razones internas ya analizadas como la crisis de partidos o incapacidad para cumplir su función mediadora, existen razones externas como el colapso del comunismo en el mundo, lo que provoca que muchos políticos que pertenecían a este segmento ideológico se lancen como independientes, y por otro lado la fuerte ideologización política que se vivía en el Perú debido a la guerra interna.

"Aparecer distintos" es lo que les permite a los outsiders generarse un espacio propio y finalmente terminar echando a los partidos del escenario político. Es por ello importante distinguir similitudes de diferencias y ver si realmente se trata de una especie distinta de la partidaria.

En ambos casos, partidos e independientes son actores que luchan por el poder, y en este proceso buscan cumplir con una función de intermediación política entre sociedad y Estado, es decir, se constituyen en actores políticos. En contextos con un sistema partidario asentado, la diferencia inmediata que saltaría a la vista sería una mayor densidad organizativa en los partidos y un definitivo sello personal entre los outsiders, pero es tal el grado de personalización de la política en el Perú que el sello personal también caracteriza a los partidos, por lo que solo podríamos decir que los outsiders llevan esta característica personal a su grado más extremo.

El acento ideológico-programático quizás podría aparecer también como una diferencia, donde los partidos serían los apegados a determinados puntos de vista, más bien rígidos y pasados de moda, y los outsiders desarrollarían un perfil pragmático. Es evidente la ausencia de un horizonte ideológico definido, al seguir las pautas de un orden secularmente dominante, 
que aparece en sus recetas como pragmáticas, y que encuentra a los outsiders entre sus portavoces más eficaces.

La diferencia entre partidos e independientes u outsiders estaría más bien dada — como ya señalamos - porque estos últimos aparecen, en momentos de crisis, como actores políticos por fuera del sistema de los partidos. Es el tipo de interacción centrado en las ganancias de corto plazo para los partidos involucrados, lo que la ciudadanía identifica como una conducta negativa y causante de los problemas que vive el país; por lo tanto, quien se coloca por fuera de esta forma de interacción en el momento adecuado tiene más posibilidades de ser identificado positivamente por la población.

Pero colocarse por fuera del tipo de interacción señalado no lleva a los outsiders a formular un nuevo tipo de interacción democrática con otros sectores políticos, particularmente si se trata de actores partidarios. Por el contrario, lo que pretenden es "jugar solos", eliminando a otros posibles actores políticos, en el entendimiento de que no se trata de adversarios sino de enemigos.

En el caso peruano del outsider Fujimori, su elección como Presidente da paso también a la formación de una coalición que lo sostiene, formada por los denominados "poderes fácticos": altos mandos militares, empresarios y funcionarios de los organismos financieros internacionales, aunque, claro, esta característica que posee Fujimori no se repite necesariamente en otros outsiders como Humala, en el 2006.

Existe, a veces, la tentación de creer que la eficacia del outsider se debe a los poderes fácticos y no a sus propias características como nuevo fenómeno político, lo que es un error; en realidad, el aspecto más importante del fenómeno outsider es el momento de su aparición, es decir, el tiempo en el que se presenta dentro de un proceso electoral dado.

Es indudable que poco podría hacer el outsider sin su alianza con la coalición de poder señalada, pero es cierto también que es su condición de outsider respecto del sistema político y el tipo de identificación que la población desarrollo con él lo que le permite aparecer como eficaz. De ninguna manera, por ello, podemos reducir la eficacia de los outsiders a la fuerza de los poderes fácticos.

La figura de outsider antipartido es más producto de la precaria institucionalización de los partidos en el Perú que de las necesidades políticas del proceso de ajuste económico en el caso de Alberto Fujimori.

Tenemos entonces que los outsiders son una especie política, pero de apariencia y discurso antipolíticos. Una especie nacida de las limitaciones de los partidos, con importantes continuidades en las formas de hacer política, en especial en lo referente a la personalización 
de esta actividad y en particular en la relación con instituciones partidarias como la jefatura que eleva la condición del líder a instancia indiscutida e indiscutible. Estas continuidades, sin embargo, tienen un punto de ruptura cuando el outsider explota su condición de actor ajeno a la sociedad política en la que irrumpe, proponiendo una forma de representación alternativa a la partidaria o lo que han llamado representación como identificación de los individuos atomizados con el líder.

Esta forma de representación como identificación es, sin embargo, contraria a la interacción democrática entre los actores políticos porque propicia una línea de comunicación vertical y arbitraria entre el líder y la ciudadanía, y promueve, a la vez, la destrucción de la comunicación horizontal, léase competencia y cooperación políticas, entre los colectivos agrupados como opinión organizada.

Esto no significa que la representación como identificación no exista en los regímenes democráticos, particularmente cuando estos son regímenes presidenciales. El problema aparece cuando esta se convierte en la forma de representación más importante. La predominancia de la representación como identificación resta drásticamente posibilidades de institucionalización al régimen democrático-representativo, y señala que los outsiders pueden constituir una alternativa de intermediación en un momento de crisis, pero no parecen tener las características necesarias para establecer patrones de funcionamiento regular en un régimen plural, cuestión indispensable para consolidar la democracia.

\section{La elección de un outsider}

La votación obtenida por Fujimori en las elecciones de 1990, en particular en los sectores populares, derivó de una desvalorización, más que de la política, de la democracia representativa y de sus instituciones, y la apuesta por un líder distinto, nuevo, con rasgos autoritarios, en la que predomina una particular valoración de la eficacia en un duro contexto de violencia y de crisis económica.

Esta eficiencia se vio concretada de manera significativa, producido ya el autogolpe de abril del 92, con la derrota de Sendero Luminoso entre 1992 -1993 y durante los años 1993 a 1995 con la implementación de una política de gasto social focalizada en aquellas zonas de pobreza extrema tanto urbanas como rurales. Esto explica el homogéneo resultado electoral a nivel nacional en 1995 (63 \%). A su vez, consideramos que el apoyo a la gestión de Fujimori se derivó de una opción razonada y pragmática, que tradujo un razonamiento costo-beneficio de una sociedad civil altamente fragmentada y desmoralizada por la violencia. Al mismo tiempo, la consolidación de fujimorismo a lo largo de la década se alimenta de la no reversión del proceso de deslegitimación de la clase política, factor central del apoyo que género el autogolpe de 1992. Como dice Martín Tanaka, en el Perú se registró propiamente el colapso 
de un sistema de partidos en su integridad, y hasta la fecha, no ha sido sustituido por ningún otro propiamente hablando.

\section{Los orígenes del outsider}

Teniendo como telón de fondo los cambios arriba señalados, es en la crisis del sistema de partidos y su ineficacia en el rol mediador donde debemos rastrear el apoyo mayoritario que Fujimori obtuvo. Pero será también resultado del duro cuestionamiento de los partidos políticos y de las llamadas "cúpulas político-partidarias", que compartía sin obstáculos para gobernar, y de la denuncia de su incapacidad para representar a la sociedad.

La crisis de los partidos peruanos se hace evidente a lo largo de la década de los ochenta debido a la incapacidad de los mismos para construir nexos estables mediante organizaciones democráticas que vertebraran las demandas de la población incorporada por las reformas sociales del régimen velasquista, esas nuevas capas populares movilizadas incorporadas al Estado "que pugnaban por hacer valer sus recientes derechos de ciudadanía".

La resultante del panorama que describimos será un definitivo desprestigio de los partidos políticos y del quehacer político como actividad articuladora del interés común. Ello permitirá la emergencia de la llamados "independientes", cuyo exponente más exitoso será sin duda Fujimori, quien consagra legitimidad mediante el denostamiento de los partidos políticos, convertidos por su discurso en "partidos tradicionales".

El rol de mediación que debían tener los partidos políticos pasa a manos del caudillo (generalmente el Presidente), quien se convierte en la encarnación y el intérprete de los intereses de la nación, en "el principal factor del interés nacional, lo cual cabe a aquel definir... autorizado a gobernar como considere conveniente”. Esto fue lo que sucedió en el Perú de los noventa.

\section{Toledo: el otro outsider 2001- 2006}

La tercera reelección de Fujimori en el año 2000 condujo la protesta popular finalmente a su derrocamiento. A lo largo de semanas de movilizaciones en todo el país y manifestaciones diarias de centenas de organizaciones democráticas en todo el territorio, se selló la emergencia y también la consolidación del liderazgo impensado del candidato Alejandro Toledo, también outsider de la política. Formado y educado en los Estados Unidos, competía con Fujimori y ganó las elecciones del 2001.

El toledismo, expresión de la crisis permanente de los partidos políticos, formó la agrupación llamada Perú Posible, precario partido organizado con fines de participar en las elecciones. En una primera etapa, con una propuesta al país, que ofrecía superar las 
limitaciones del fujimorismo (creación de empleo), con un compromiso para la renovación y revisión el planteo neoliberal de la década de los noventa, con un personal tecnocráticoindependiente altamente calificado (llamado el equipo de "todas las sangres"), convocado por Toledo. Estos objetivos se dirigieron a promover una reinstitucionalización y relegitimación de las instituciones democráticas, que el fujimorismo había virtualmente destruido en su búsqueda de compromiso obligado con el proyecto reeleccionista.

La agrupación Perú Posible era una organización estructurada en torno a la participación en la marcha de los Cuatro Suyos. Carentes de una ideología básica que cohesione a los militantes que se acercaban al partido del gobierno, el objetivo de la militancia se convirtió, sobre la base de una visión del aparato del Estado como fuente de empleo, en una forma de compensación a los esfuerzos desplegados en las movilizaciones.

En el estricto sentido, no es, pues, un partido político, en la medida no solo que no tiene una ideología sino tampoco una estructura organizativa estable que funcione como aparato, y carece a todas luces de cuadros calificados para cubrir la dirección y orientación de la administración pública y enfrentar las reformas del Estado que resultan perentorias para ganar eficacia y fluidez. Estas características las mantuvo tanto en sus orígenes (1995) como en los tiempos actuales (elecciones 2010 y 2011). Se trata, por tanto, básicamente de una organización con fines electorales que gira en torno a la figura de Alejandro Toledo.

Las agudas pugnas al interior de Perú Posible muestran al partido como lo que es en realidad: una asociación de independientes con proyectos personales y ambiciones políticas y personales que gravitan en torno a diversos círculos del poder cercanos a Palacio. Y donde por cierto no existe mecanismo institucional alguno para resolver los conflictos internos que trascienden, dando la imagen de un partido disperso y caótico.

\section{Perú: la persistencia de los outsiders y los retos para la democracia}

Hasta setiembre de 2005, seis meses antes de las elecciones generales del 9 de abril de 2006, tres candidatos aparecían en los primeros lugares de las encuestas: Lourdes Flores Nano, por la coalición Unidad Nacional; Valentín Paniagua, por el Frente de Centro; y Alan García, por el APRA. Pero todo cambió a fines de 2005, cuando irrumpió la candidatura del comandante Ollanta Humala, líder del novísimo Partido Nacionalista del Perú. En pocas semanas, amagaba el primer lugar en las encuestas. Había aparecido, entonces, el outsider esperado por todos los analistas, lo que recompuso el panorama electoral. ${ }^{1}$

1 Haya de la Torre, Agustín. Perú: la persistencia de los outsiders y los retos para la democracia. 
Este fenómeno - personajes que provienen de los márgenes de la política y que de pronto concitan la expectativa popular- no es nuevo. El precursor de esta tendencia en el caso peruano fue Ricardo Belmont, entonces joven y locuaz empresario de radio y televisión que ganó la alcaldía de Lima en 1989, tras derrotar a los candidatos de los partidos más fuertes.

En 1990, cuando todo hacía prever que el novelista Mario Vargas Llosa, líder de la coalición de derecha Frente Democrático, se impondría en las elecciones presidenciales sobre sus rivales del APRA y de Izquierda Unida, apareció la figura de Alberto Fujimori, ex rector de la Universidad Agraria. Fujimori cambió por completo el esquema vigente: derrotó ampliamente a Vargas Llosa, oponiéndose a las medidas económicas neoliberales, aunque, una vez en el poder, fue su más implacable ejecutor.

En los comicios de 2000, dos candidatos aparecían como los rivales más fuertes del autoritario gobernante: Alberto Andrade, Alcalde de Lima, y Luis Castañeda, ex-Presidente del Seguro Social nombrado por el propio Fujimori. Salidos de antiguos partidos —el Partido Popular Cristiano y Acción Popular-, ambos habían formado sus propios movimientos electorales.

Sin embargo, en los últimos tres meses de campaña apareció la figura de un nuevo candidato, Alejandro Toledo, quien en 1995 había tenido escasa suerte.

Sorpresivamente, este economista de origen campesino y quechua consiguió el apoyo popular que le había sido negado rotundamente cinco años antes.

Fujimori dudó en imponer su triunfo en la primera vuelta. Si bien tenía todavía un fuerte respaldo popular, no era garantía suficiente para superar la mitad de los votos. El control que el SIN ejercía sobre el sistema electoral le permitió mantener en vilo al país durante los días siguientes a la elección, anunciando resultados que amagaban por décimas el $50 \%$. Finalmente, aceptó ir a la segunda vuelta, pero Alejandro Toledo denunció fraude y decidió no participar.

Esto le permitió a Fujimori inaugurar su tercer periodo en el poder. Toledo, como presidente desde 2001, nombró a Ollanta Humala como su agregado militar en París y luego en Seúl.

Para el 2006, Ollanta Humala, aunque no alcanzó a regularizar la inscripción de su Partido Nacionalista Peruano (logró reunir las 125000 firmas exigidas y constituyó los 65 comités provinciales, pero se vencieron los plazos para registrar su candidatura). Consiguió seguir en carrera gracias a la salida de emergencia que, luego de varios intentos, encontró en la interesada acogida de la agrupación Unión por el Perú (UPP). 
La UPP es un movimiento que en 1995 lanzó al ex-Secretario general de las Naciones Unidas, Javier Pérez de Cuéllar, como candidato a Presidente. El embajador se desligó luego de su derrota, pero el partido obtuvo pequeñas representaciones parlamentarias en 2000 y 2001. En la actualidad, está dirigido por un grupo de políticos que poco tienen que ver con el proyecto original, y se ha transformado en uno de las tantas fuerzas que subsisten porque tienen registro legal, aunque no votantes. Han sido calificados acertadamente como "vientres de alquiler", y eso es justamente lo que necesitaba Ollanta Humala para regularizar su postulación.

Si bien en las elecciones del 2006 Ollanta Humala no logra ganar las elecciones, lo consigue cinco años después, cuando el 2011 vuelve a presentarse como candidato de su Alianza Electoral Gana Perú y consigue derrotar a la hija del ex presidente Alberto Fujimori, es decir, como en casos anteriores, el outsider llega a hacerse de la presidencia.

¿Cómo explicar todos estos fenómenos en la política nacional? Una respuesta bastante interesante la encontramos en el trabajo de Julio Cotler, quien identifica estos fenómenos con los cambios de escenarios y actores que se han ido produciendo no solo en el Perú sino en toda América Latina.

Para Cotler, las expectativas generadas por la transición a la democracia indujo a los contrapuestos actores sociales y políticos a extremar sus exigencias al Estado, es decir, se produjo un incremento exagerado de las expectativas de la población que los partidos tradicionales no supieron manejar adecuadamente, lo que condujo a la realización de promesas incumplidas y la desilusión del electorado y su posterior búsqueda de nuevos actores que fuesen en contra de dichos partidos.

Estas contradicciones intensificaron el conflicto y desbordaron las mediaciones políticas. La debilidad o inexistencia de un sistema de partidos condicionó este desenlace, y la clásica fragmentación política y social determinó que fueran desoídas y rechazadas las convocatorias para morigerar las demandas y concertar los diversos intereses.

El resultado de la conjunción de estas transformaciones políticas y culturales ha sido el surgimiento de outsiders, representantes de estos nuevos actores y valores antipolíticos. Los outsiders son ajenos y contrarios a la "clase política", o, en su defecto, persiguen desembarazarse de los compromisos políticos contraídos. Collor y Fujimori; Víctor Paz Estenssoro, Jaime Paz Zamora, Carlos Menem y Carlos A. Pérez son casos ejemplares de estas nuevas situaciones.

Estos "nuevos caudillos" (Perelli, 1992) recuerdan los tradicionales liderazgos populistas porque denuncian los vicios e injusticias del sistema institucional y prometen resolver, personalmente, los agravios y las aspiraciones de las frustradas y desamparadas masas, concitando su respaldo. En 
las condiciones de relativa desarticulación institucional, las encuestas de opinión y los medios de comunicación recogen y difunden estos sentimientos, constituyendo las bases de legitimación para "el retorno del líder" de las "democracias delegativas", mediante fórmulas y relaciones plebiscitarias (O’Donnell, 1992; Zermeño, 1989; Cotler, 1993). ${ }^{2}$

Pero si el estilo de comportamiento y las relaciones de los outsiders con las masas se emparentan con aquellos liderazgos populistas, responden a los enunciados de las fuerzas neoconservadoras que han emergido en América Latina, siguiendo la ola mundial (Chalmers, 1992).

Su rechazo a la clase política y, en general, a la institucionalidad — que denominan laxamente de "populista" - se basa en su naturaleza anacrónica con las nuevas realidades nacionales e internacionales, motivo de su ineficacia y desprestigio. El carácter clientelista y prebendario de los partidos y del Estado sería fundamento del desmanejo gubernamental y la corrupción, del atraso y de la injusticia social. A su vez, la colonización de la sociedad por dichas instancias políticas habría generado prácticas "rentistas" al servicio de intereses particulares, que bloquean el desarrollo de las iniciativas individuales y del mercado.

El amplio respaldo internacional a la aplicación del recetario neoliberal y la carencia de alternativas válidas han favorecido que ese dilema entre democracia y autoritarismo se arraigue en diferentes sectores sociales, y que apoyen la restricción a la democracia —aunque temporalmente- a fin de que los outsiders puedan realizar las transformaciones económicosociales como medio para lograr en un futuro, orden, bienestar y estabilidad. Es decir, se aceptaría una suerte de "necesidad histórica" de un primer tiempo "político", marcado por la restricción a la participación democrática, para dar paso a un segundo tiempo "económico-social".

En 1980, la transición a la democracia en el Perú, como en otros casos, concitó las esperanzas de las mayorías populares y de los sectores medios de ver realizados sus seculares reclamos ciudadanos. Diez años más tarde, no quedaba sino desengaño y desesperación; el tradicionalmente débil Estado se encontraba en bancarrota; los partidos estaban desacreditados y arrastraban consigo a las organizaciones de la sociedad.

La subversión, el narcotráfico, la creciente intervención militar en los asuntos públicos, la violación de los derechos humanos y, por si faltara algún otro flagelo, la hiperinflación se concentraron para que la desintegración política y social fuera considerada como una seria posibilidad.

Las tradicionales y profundas jerarquías y desigualdades sociales — con sus connotaciones étnicas, raciales y regionales - fueron duramente cuestionadas políticamente a fines de los

2 Cotler, Julio. "Crisis política, outsiders y democraduras: el fujimorismo". 
años cincuenta; la culminación de este proceso fue la crisis del régimen oligárquico-colonial y la constitución del Gobierno Revolucionario de la Fuerza Armada en 1968. Este emitió una serie de reformas para nacionalizar y democratizar, por la vía autoritaria, las estructuras sociales e institucionales destinadas a consolidar la integración nacional; y, gracias al crédito externo, abultó las funciones productivas y distributivas del Estado, a fin de legitimarlo y fortalecerlo.

Pero, al bloquear la participación política, el gobierno militar procuró la irrupción de las fuerzas que había contribuido a crear y movilizar con sus reformas y discursos de corte populista y nacionalista. Desde 1975, el agotamiento de las posibilidades redistributivas del gobierno y la crisis fiscal contribuyeron a que las radicalizadas presiones sociales, las exigencias de los organismos internacionales de crédito y los apremios de la administración Cárter forzaran la transición democrática, hecho que se concretó en 1980.

Los "jefes", que regían de manera cuasi patrimonial sus organizaciones políticas, retomaron la representación parcelada de segmentos sociales ciñéndose a contrastadas ideologías. Las emergentes izquierdas marxistas y maoístas reprodujeron esos rasgos y mantuvieron una permanente competencia por el control del "movimiento popular", radicalizando sus demandas "hasta sus últimas consecuencias". En consecuencia, la tradicional fragmentación política se renovó y se reforzaron las varias y profundas divisiones que históricamente han marcado a la sociedad peruana (Cotler, 1993).

Durante los dos primeros años del gobierno de Belaúnde, en su segundo mandato, su control personal sobre la mayoría de los congresistas le permitió, mal que bien, torear las críticas sociales y las acusaciones de violación de los derechos humanos en la lucha que los militares llevaban contra la subversión iniciada en 1980. Pero, este irresponsable comportamiento contribuyó a que arreciara la desconfianza al gobierno y que la concepción "formal" de la democracia cobrara fuerza.

La confluencia de todos esos fenómenos contribuyó a dar un vuelco en el estado de ánimo de la sociedad, que se reflejó en los resultados electorales. Las izquierdas legales, aparentemente unidas, lograron importantes éxitos electorales en 1983, que llevaron a que su candidato presidiera la Municipalidad de Lima, y que Alan García, dirigente del APRA que se había despuntado como líder de la oposición, ganara las elecciones presidenciales de 1985.

Si en 1980 Belaúnde obtuvo una confortable mayoría (45\%), el candidato de su partido obtuvo en 1985 solo el $7 \%$; mientras que el APRA, que entonces había obtenido 27\%, ahora, con García, conquistaba el 53\%. Por último, mientras que la suma de los votos de AP y del PPC alcanzaba el 20\%, los votos del APRA y de IU comprendían las tres cuartas partes del electorado. 
Es así como, a mediados de la década de los ochenta, el país se desenvolvía en diferentes escenarios y con diversos actores legales e ilegales, divididos y enfrentados, dando claros indicios de la dispersión política. El sorprendente triunfo de García y del APRA, que durante 55 años había sido impedido de alcanzar el poder, prometía llevar a cabo, democráticamente, las transformaciones destinadas a resolver los viejos y nuevos problemas, y avanzar en la construcción nacional-estatal. Lo atestiguaba el entusiasmo juvenil de García para ser un "presidente de todos los peruanos" y llevar adelante su programa "democrático, nacional y popular”.

De entrada, García se enfrentó a los organismos internacionales de crédito, al decidir unilateralmente destinar solo el equivalente del $10 \%$ del valor de las exportaciones al pago de la deuda externa. Esta decisión, que competía con la propuesta por Fidel Castro, le concedió la notoriedad que García proyectó a su política internacional "tercermundista" y no alineada".

El terremoto político que inició esta disposición agudizó la clásica fragmentación política y dio indicios evidentes de arrastrar al país a profundas divisiones y transformaciones que, en las condiciones en que se desarrollaba la subversión, hicieron temer por el futuro del país.

El rechazo a los "políticos" se mostró en las elecciones municipales de 1989, cuando el grueso de los votantes se inclinó por los "independientes", anticipando lo que parecía ser el seguro triunfo de Vargas Llosa; mientras tanto, las encuestas a las que el presidente García era adicto, indicaban que contaba con la adhesión de solo el $15 \%$ de los entrevistados, proporción que el último año de su gobierno cayó al 7 \%.

Sin embargo, la asociación de Vargas Llosa con los desprestigiados partidos y jefes de AP y del PPC lo calificó como un insider. Asimismo, el sustento económico de los capitalistas, evidenciado en su millonaria campaña publicitaria, favoreció que el imaginario popular lo identificara con los "peces gordos", que, como lo había escrito en una de sus novelas, son percibidos como los agentes de la dominación.

La falta de otra alternativa que las desprestigiadas candidaturas del APRA y de las divididas izquierdas condicionó que nuevas representaciones sociales abrieran paso a una corriente de opinión que respondía a la convocatoria del ingeniero Alberto Fujimori, este sí un auténtico outsider.

Los resultados electorales dieron cuenta de los realineamientos políticos y sociales que se habían advertido en las elecciones municipales. Mientras en 1980 y 1985, los partidos recogieron el $97 \%$ de los votos, en 1990 se redujeron en más de un tercio, diferencia que se trasladó a Cambio 90, la agrupación de Fujimori. 
En la segunda vuelta, para dirimir cuál de los dos candidatos más votados obtenía más del 50\% de los votos requeridos para ser proclamado presidente, los izquierdistas y los apristas votaron contra Vargas Llosa, decidiendo la elección de Fujimori. Los resultados electorales mostraron el carácter socialmente segmentado de la contienda y los claros apoyos populares del ganador (Rospigliosi 1991). Pero rápidamente Fujimori se deshizo de los compromisos contraídos con sus electores y se alineó con sus contrincantes. Los peruanos aprenderían que, como en el juego de naipes, "nadie sabe para quién trabaja" cuando se trata de un outsider.

A raíz del inusitado triunfo electoral en 1990 y el golpe de estado que decretó en abril de 1992, Fujimori se convirtió en símbolo del outsider exitoso. En la región, los presidentes Paz Zamora de Bolivia y Rodrigo Borja de Ecuador, enfrentados a sus respectivas legislaturas, amenazaron seguir los pasos de Fujimori y disolver el Congreso. En Guatemala, el Presidente Serrano fracasó en su intento de asumir poderes totales debido a la rápida reacción de la nueva administración norteamericana. En Venezuela, la crisis de los partidos y el enfrentamiento entre los poderes han creado fuertes simpatías a los procedimientos fujimoristas. En Brasil, diversos políticos y militares han insinuado la posibilidad de soluciones análogas, mientras que el Presidente Itamar Franco, sus ministros e incluso miembros de las fuerzas armadas se han declarado explícitamente contrarios al "fujimorismo".

Más allá de la región, Ross Perot y Boris Yeltsin han sido asociados con este fenómeno, motivando que Fujimori no tuviera empacho en declarar que "tengo derecho al copyright" (sic) ante las decisiones del ejecutivo ruso de clausurar el Parlamento. La crítica situación de los partidos en Italia y la emergencia de outsiders antidemocráticos en este y en otros países europeos igualmente han merecido que se haga referencia al presidente peruano.

Por esto, la restauración del poder estatal se constituyó en el objetivo prioritario de sectores estratégicos, que asumieron la razón de Estado como fuente de justificación. Por sus orígenes étnicos, que lo aislaban de la élite social, por su naturaleza de outsider político y por los rasgos de su personalidad, Fujimori adoptó a cabalidad dicho objetivo, para lo cual todo era válido (Jochamovitz, 1993).

Para la elección municipal, que se realizó dos meses más tarde, en enero de 1993, el gobierno modificó la legislación electoral para favorecer la proliferación de candidaturas y deslucir a los partidos, que en esta oportunidad sí decidieron participar. Pero el candidato oficial de Lima, donde radica más de la tercera parte del electorado, tuvo que retirarse antes de sufrir una derrota contundente; en tanto que las listas "independientes" obtuvieron el doble de votos de las elecciones municipales de 1989 al concentrar el $61 \%$ de las preferencias, y los candidatos de los partidos se redujeron a 36\% — cuando en 1989 habían obtenido el $71 \%$ - pero igual ganaron las alcaldías de varias ciudades importantes del país. 
Lo anterior significa que el incremento de movimientos independientes tiene además una motivación política en los tiempos del fujimorismo: desacreditar, desprestigiar aún más a los partidos políticos tradicionales hasta hacerlos desaparecer; eso, agregado al discurso del presidente de ataque permanente contra los partidos político, hace que el Perú viva una etapa de outsiders en la política no solo nacional sino que tiene su reflejo también en los ámbitos subnacionales, como los gobiernos distritales y provinciales.

En tiempos más recientes, los movimientos llamados independientes han cedido el paso a los movimientos regionales, organizaciones que fueron creadas a partir del proceso de descentralización regional que se dio en el país a partir del 2002, y que trae consigo la aparición de caudillos regionales que articulan sus movimientos en torno a sus personas, que inicialmente se tratan de outsiders pero que en el transcurso de este tiempo han ido consolidando sus organizaciones en desmedro de los partidos de alcance nacional.

Por otro lado, se han realizado modificaciones al sistema electoral que pretenden fortalecer la presencia de los partidos políticos, por ejemplo elecciones internas, valla electoral, o un mayor número de requisitos para la inscripción de nuevas organizaciones políticas; pero ello en la práctica no ha impedido la aparición de nuevos outsiders, los que creemos tienen su origen en la crisis misma de los partidos políticos.

\section{Conclusiones}

1. Los outsiders son un fenómeno político que se caracteriza por irrumpir de forma abrupta en el escenario político, logrando en muchos casos hacerse de victorias electorales y en otras ocasiones quedando en un expectante segundo lugar.

2. En el caso peruano, este fenómeno se inicia a fines de los años ochenta, y tiene su máxima expresión en la figura de Alberto Fujimori.

3. Las causas que han dado origen a los outsiders en el Perú han sido principalmente tres: la crisis de los partidos políticos, que se expresa en el descrédito de los mismos y en la ineficacia en su función mediadora con la sociedad, la alta volatilidad electoral que es una consecuencia de la baja identificación partidaria en el electorado peruano y un sistema electoral permisible a la presencia de organizaciones que solo se articulan para presentarse en los procesos electorales y luego desaparecen de la escena nacional.

4. Los outsiders en el caso peruano se han dado en diferentes niveles de gobierno, así como a lo largo de casi 30 años, sin poder decir que sea un fenómeno del pasado. Lo más probable es que, dadas las condiciones políticas, sociales y económicas por las que pasa el país, periódicamente aparezcan nuevos outsiders. 


\section{REFERENCIAS}

- Balbi, Carmen Rosa. Figura y repertorio del outsiders en el Perú. 2005.

- Cotler, Julio. "Crisis política, outsiders y democraduras: el Fujimorismo”, en: Sociedades, crisis y cambio. Lima, 2001.

- Duff, Ernest. Leader and Party in Latin America. Boulder: Westview Press, 1985.

- Duverger, Maurice. Political Parties. London: Metheun \& Co., Ltd., 1954.

- Gonzales, Osmar Alberto. Para garantizar la autocracia. Fuerzas armadas y fujimorismo en el Perú de los años 90.

- Hauss, Charles; Rayside, David. "The Development of New Parties in Western Democracies Since 1945”, en: Maisel, Louis; Cooper, Joseph (eds.). Political Parties: Development and Decay. Beverly Hills: Sage Publications, 1978.

- Haya de la Torre, Agustín. "Perú: la persistencia de los outsiders y los retos para la democracia". Revista Nueva Sociedad, marzo, 2006.

- Lawson, Kay. The Comparative Study of Political Parties. New York: St. Martin's Press, 1976.

- Lawson, Kay, Merkl, Peter H. (eds.). When Parties Fail: Emerging Alternate Organizations. Princeton: Princeton University Press, 1988.

- Lipset, Seymour Martin; Rokkan, Stein. Party Systems and Voter Alignments: CrossNational Perspectives. New York: The Free Press, 1967.

- Mair, Peter. "Party Organizations: From Civil Society to the State", en: Katz, Richard S., y Mair, Peter (eds.). How Parties Organize. London: Sage Publications, 1994.

- _ _ (ed.) The West European Party System. Oxford: Oxford University Press, 1990.

- Melucci, Alberto. Sistema político, partido y movimiento social. Milan: Feltrinelli, 1997.

- Michels, Robert. Political Parties. New York: Dover, 1959.

- Nohlen, Dieter (coord.). Enciclopedia electoral latinoamericana y del Caribe. San José: Instituto Interamericano de Derechos Humanos, 1993.

- Panebianco, Angelo. Modelos de partidos. Madrid: Alianza, 1990

- Offe, Claus. Partidos políticos y nuevas movimientos sociales. Madrid, España: Edit. Sistemas, 1988. 
- Rial, Juan. "Los partidos políticos en América del Sur en la primera mitad de los años noventa", en: Perelli, Carina; Picado S., Sonia; Zovatto, Daniel (comp.). Partidos y clase politica en América Latina en los noventa. San José: Instituto Interamericano de Derechos Humanos, Centro de Asesoría y Promoción Electoral (Capel), 1995.

- Riker, William H. "The Two-Party System and Duverger's Law: An Essay on the History of Political Science", en: American Political Science Reviejo, 1982, 76: 753-766.

- Sartori, Giovanni. Parties and Party Systems: A Frametvork for Analysis. Cambridge: Cambridge University Press, 1976.

- Taagepera, Rein; Shugart, Matthew Soberg. Seats \& Votes: The Effects \& Determinants of Electoral Systems. New Haven: Yale University Press, 1989.

- Ware, Alan. Citizens, Parties and the State: A Reappraisal. Princeton: Princeton University Press, 1987. 


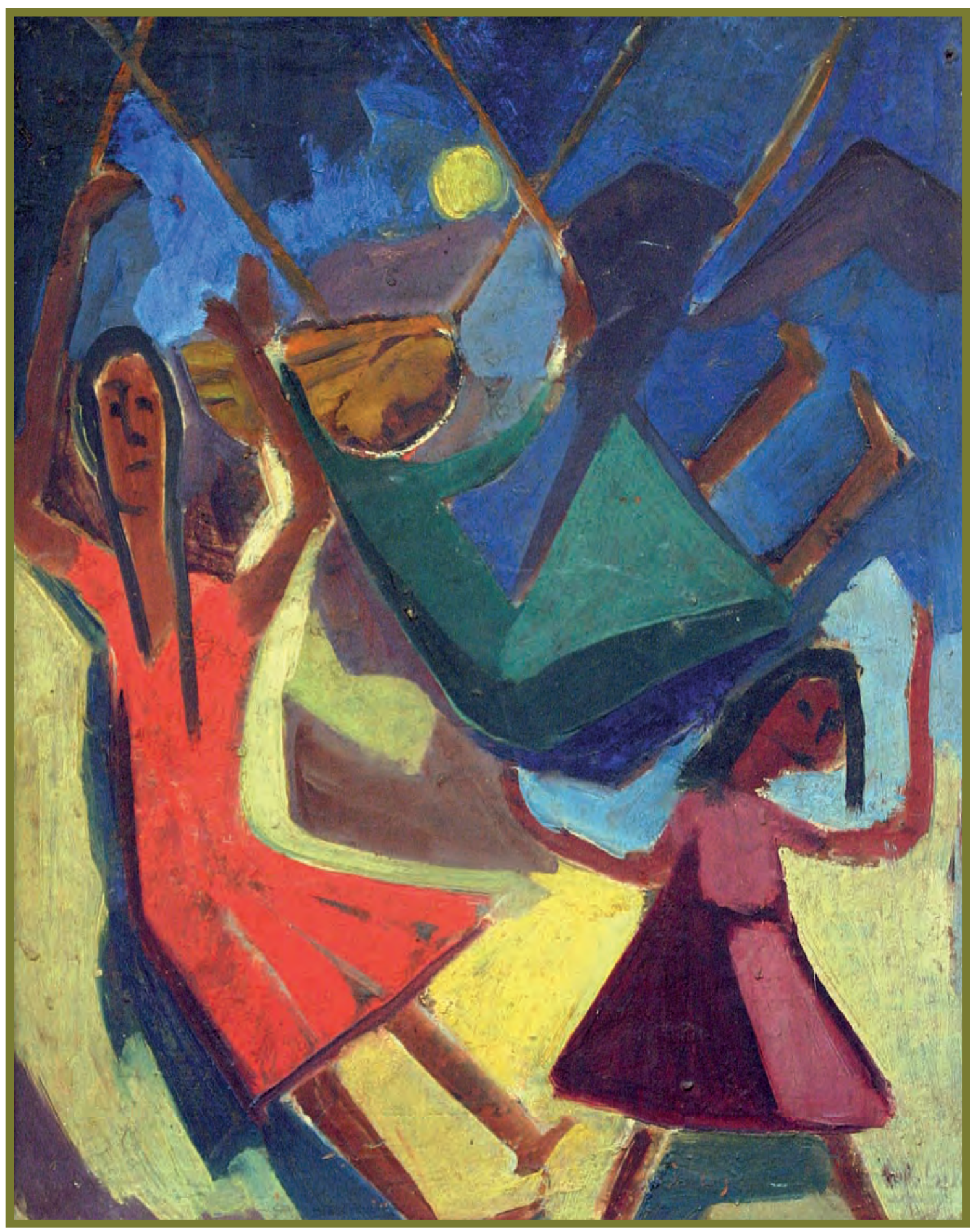

Los columpios. 